\title{
Experimental and CFD analysis on heat transfer and fluid flow characteristic of a tube equipped with variable pitch twisted tape
}

\author{
Sagar Paneliya ${ }^{1}$, Parth Prajapati ${ }^{1}$, Umang Patel $^{2}$, Ingit Trivedi $^{2}$, Anshu Patel $^{2}$, \\ Krunal Patel $^{2}$, and Sakshum Khanna ${ }^{1, *}$ \\ ${ }^{1}$ School of Technology, PanditDeendayal Petroleum University, Gujarat, India \\ ${ }^{2}$ Department of Mechanical Engineering, SVBIT, Vasan, Gujarat, India
}

\begin{abstract}
In this paper, we report an experimental and Computational Fluid Dynamics (CFD) investigation on the overall heat transfer coefficient, friction factor and effectiveness of a tube equipped with classic and variable twisted tape inserts. Constant $(\mathrm{Y}=4.0)$ and variable pitch twisted inserts $(\mathrm{Y}=4-3-4)$ made of Stainless Steel and Aluminium were used during the experiments due to their ease in machinability. Resistance thermometers were used to measure temperature of the working fluid at the inlet and outlet of the test section. It was observed that the twisted tape in the tube imposes the turbulence in the fluid and enhances the heat transfer due to swirling flow. The results showed that the overall heat transfer coefficient and effectiveness of aluminium variable pitch twisted tape were higher than stainless steel inserts. The experimental data obtained were validated using Computational Fluid Dynamics (CFD) simulations. The constant pitch inserts for aluminium and stainless steel showed an enhancement of $67.54 \%$ and $66.65 \%$ as compared to plain tube. Whereas aluminium variable pitch inserts showed an enhancement of overall heat transfer coefficient by $18.15 \%$ as compared to constant pitch insert and stainless-steel variable pitch insert showed enhancement of $15.25 \%$ as compared to constant pitch insert.
\end{abstract}

\section{Introduction}

High-performance heat transfer system (HTS) is of great importance in many industrial applications. Heat transfer augmentation techniques can be divided into two major categories: Passive and Active. Inan active HTS, an object uses an external energy to enhance the heat transfer rate (HTR) whereas; in passive HTS an object is independent of the external energy. These techniques are used in various industries working with heat exchanger system i.e. automobiles, thermal power plants, refrigerators, air-conditioning equipment etc. A wide range of inserts has been utilized for enhancing the heat transfer

\footnotetext{
*Corresponding author: sakshum.kphd16@sot.pdpu.ac.in
} 
which includes coil, wire, brush, mesh, strip, twisted tape etc. [1-2]. Nowadays, twistedtape inserts are widely applied in HTS due to enhanced thermal performance at low cost.

The twisted tape insert in a tube generates swirl flow and modifies the side wall velocity profile due to the random vorticity distributions in the vortex core [1]. In turbulent flow, the pair of swirls in the tube with a twisted tape insert is characterized by uniform axial velocity in a form of vortexes that exist in any sectional plane of the tube [2]. The fluid mixing near the wall region and duct core is improved due to the swirl induced tangential flow velocity component. In comparison with the smooth tube, internal spiral groove impart swirl to the axial flow in the near region of the tube wall as well as induced heat transfer enhancement and assist in improving the surface roughness [3]. In such tubes, the flow Reynolds number $(\mathrm{Re})$ and twist ratio $(\mathrm{Y})$ of twisted tape are the controlling parameters to determine the pressure drop and heat transfer characteristics. Several investigations have been performed to increase HTR using classic and twisted tape inserts. In 2006, Eiamsa-ard et al. experimentally investigated the heat transfer and friction factor characteristic in double pipe heat exchanger with classically twisted tape inserts [4]. Their results revealed an enhancement in heat transfer coefficient with a decrease in twist ratio. They also showed that a decrease in the space ratio can improve both the friction factor and heat transfer coefficient. Sarma et al. [5] tried to derive the generalized co-relation of pressure drop and heat transfer in a tube with the normal twisted tape insert using the experimental data mining. It was observed that due to the presence of a twisted tape in the tube, it inhibited the transitional jump from laminar to turbulent flow which led to the monotonic laminar to turbulent transition. But, due to the persisting flow fluctuations in turbulent flow that inherits the better fluid mixing to the near wall tube, heat transfer augmentations in the tube with twisted tape insert fall dramatically in the turbulent flow regimes; but increase with the decrease of twist ratio (Y) [6]. Recently, Chang et al. investigated heat transfer enhancement in the tube fitted with serrated twisted tape [7]. They compared the different twisted tape (based on power consumption) with different twist ratio. The results obtained experimentally showed an increase in the Nusselt number and friction factor with a decrease in the twist ratio. The twisted tape with variable twist ratio increases the turbulent flow and heat transfer rate depending upon the twist ratio $(\mathrm{Y})$ of the tape.

In this paper, the heat transfer and pressure drop characteristics of laminar, transient and turbulent flows in the tubes fitted with different twisted tape inserts is reported. Further, the experimental results were validated with CFD simulations in an order to determine the heat transfer rate of the tube. Remaining sections of the paper are organized as follows Section 2 describe the experimental set up to determine the heat transfer characteristics of the fluid. The results obtained from the experiments are discussed and reported in the section 3 . Finally, the conclusion of the present work is reported in the section 4.

\section{Experimental apparatus and procedure}

Figure 1 shows the experimental set up of the test section along with sensors and controller. The heat transfer characteristic of the water flowing through concentrated tube was studied using constant and variable pitch twisted tape inserts. The water at $36^{\circ} \mathrm{C}$ was supplied from an overhead tank to inner annulus of the tube and drained out into the underground tank. The water level in the overhead tank was maintained constant through an overflow line. Hot water was supplied to the outer annulus of the tube by a centrifugal pump and drained back into the hot water tank. Wooden flanges were used to provide structure support to the test section. The rubber gaskets were used to eliminate leakages and rubber bellow was used to minimise vibrations and pulsations generated because of high velocity of water. Resistant temperature detectors (RTD) were used to measure the temperature at various intermittent 
section of the tube. A U-tube manometer was used to measure pressure drop of the fluid across the tube. The mass flow rate of water was measured and regulated using a rotameter. To maintain constant heat flux, a layer of asbestos thread and aluminium foil was wrapped around the test section as shown in Figure 1. Modified variable pitch twisted tape was used to enhance the heat transfer coefficient. Stainless steel and Aluminium twisted tape inserts were used as passive heat transfer enhancement technique in this experiment. The twist ratio of aluminium and stainless steel were obtained by using a Lathe machine as described in Table 1.

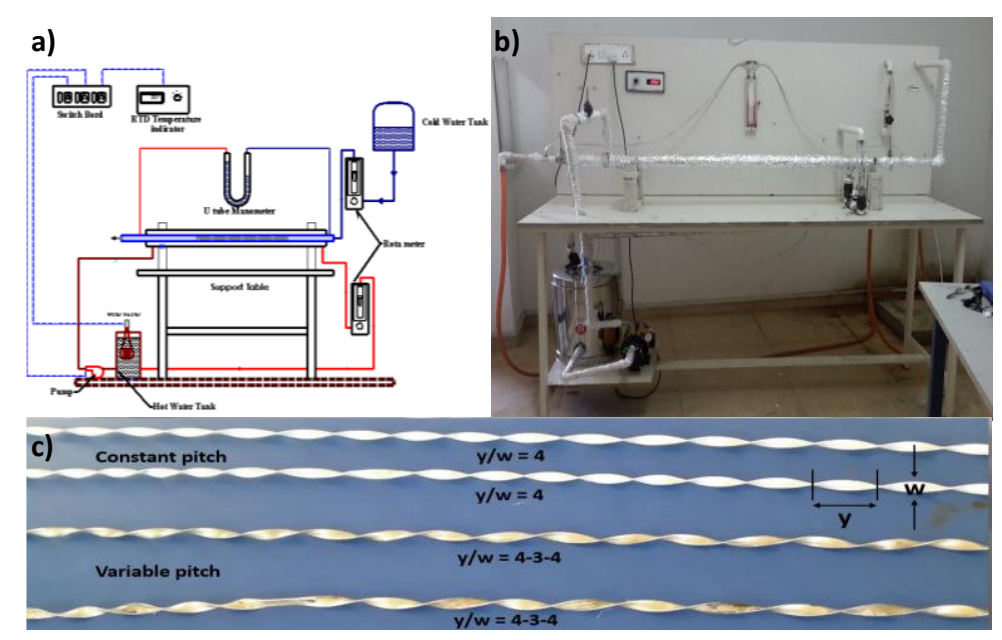

Fig. 1. A Schematic diagram and the experimental setup are shown in 1 (a) and 1 (b). The employed constant and variable pitch twisted tape inserts in tube are shown in 1 (c).

Table 1. Dimensional parameters of twisted tapes.

\begin{tabular}{|c|c|c|}
\hline Parameters & Constant pitch & Variable pitch \\
\hline Length & $1.5 \mathrm{~m}$ & $1.5 \mathrm{~m}$ \\
\hline Twist ratio (Y) & 4 & $4-3-4$ \\
\hline Diameter & $16 \mathrm{~mm}$ & $16 \mathrm{~mm}$ \\
\hline Material & Stainless Steel \& Aluminum & Stainless Steel \& Aluminum \\
\hline
\end{tabular}

Counter-flow configuration was used for the working fluid in the test section. The hot water at $60^{\circ} \mathrm{C}$ was supplied with a constant mass flow rate of $60 \mathrm{Lph}$ throughout the test section. Simultaneously, the mass flow rate of cold water through the inner annulus was varied from $40 \mathrm{Lph}$ to $180 \mathrm{Lph}$ at the interval of $20 \mathrm{Lph}$. The temperature and pressure drop of hot and cold water at the inlet and outlet was measured and same process was repeated for classic and variable pitch twisted tape inserts.

\section{Thermal models}

Well-developed heat transfer correlations were used to determine the heat transfer rate of the water.

$$
Q=m C_{p}\left(T_{c i}-T_{c o}\right)
$$


Logarithmic Mean Temperature difference of water at inlet and outlet was calculated using Eq. 2.

$$
L M T D=\frac{\left(T_{h o}-T_{c i}\right)-\left(T_{h i}-T_{c o}\right)}{\ln _{h o-T_{c i}}}
$$

where $\mathrm{T}_{\mathrm{ho}}, \mathrm{T}_{\mathrm{hi}}, \mathrm{T}_{\mathrm{co}}, \mathrm{T}_{\mathrm{ci}}$ are the temperatures of hot and cold water at outlet and inlet of the tube respectively.

Overall heat transfer coefficient, Nusselt number, effectiveness and friction factor was calculated using Eq. (3)-(11).

$$
\begin{gathered}
U=\frac{Q}{A \times L M T D} \\
\mu=\left(3 \times 10^{-8} \times \mathrm{T}_{\mathrm{avg}}{ }^{4}\right)-\left(9 \times 10^{(-6)} \times \mathrm{T}_{\mathrm{avg}}{ }^{3}\right)+\left(0.001 \times \mathrm{T}_{\mathrm{avg}}{ }^{2}\right)-\left(0.058 \times \mathrm{T}_{\mathrm{avg}}\right)+1.778 \\
v=\frac{4 m_{c o}}{\pi \times d_{i^{\wedge}} 2} \\
\operatorname{Pr}=\frac{\mu \times C p}{K} \\
\operatorname{Re}=\frac{1000 \times V \times d_{i}}{\mu} \\
N u=0.023 \cdot\left(\operatorname{Re} e^{0.8}\right) \cdot\left(\operatorname{Pr} r^{0.4}\right), \text { for } R e<4000 \\
N u=0.023 \cdot\left(\operatorname{Re} e^{0.8}\right) \cdot\left(\operatorname{Pr}^{0.33}\right), \text { for } \operatorname{Re}>4000 \\
\varepsilon=\frac{Q}{C_{\min }\left(T_{h i}-T_{c o}\right)} \\
f=\frac{\Delta P}{\left(\frac{L}{D}\right)\left(\frac{\rho U^{2}}{2}\right)}
\end{gathered}
$$

\section{Results and discussion}

\subsection{Experimental observations}

The experimental study of heat transfer for tubes fitted with and without twisted tape insert was calculated and reported. The enhancement of the heat transfer rate and overall heat transfer coefficient with mass flow rate of cold water is shown in Figure 2 (a) and 2 (b) respectively. Since heat transfer rate is largely dependent on specific heat and mass flow rate, it was observed that the heat transfer rate was significantly lower at low mass flow rate. Among all the configurations of inserts, maximum heat transfer rate was observed for aluminum variable pitch twisted tape. Moreover, aluminium variable twisted tape inserts showed improved overall heat transfer coefficient compared to stainless steel with same configuration. The augmentation of heat transfer rate and overall heat transfer coefficient in aluminium variable pitch twisted tape is due to the high thermal conductivity of aluminium as compared to the stainless steel. This indicates the importance of twist ratio and conductive materials used as an insert in the tube leading towards enhancement of heat transfer. The effectiveness of heat transfer augmentation for different configurations of tube 
inserts are shown in Figure 3 (a). The effectiveness $(\varepsilon)$ is indexed by the ratio of actual heat transfer rate (cold fluid) to maximum heat transfer rate. As shown in the figure 3 (a), the $\varepsilon$ at various fluid flow rates was observed to be lower for plain tube when compared to constant and variable pitch inserts.
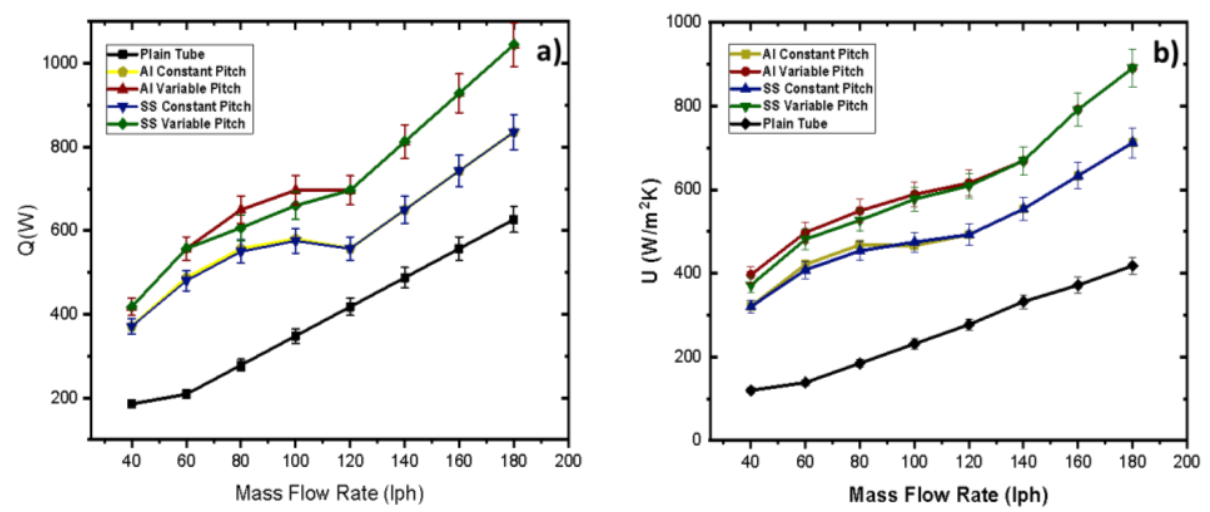

Fig. 2 (a). Plotted graph between heat transfer rate (Q) and mass flow rate (Lph) of cold water for various twisted tape inserts (b) Plotted graph between overall heat transfer coefficient (U) and mass flow rate (Lph) for various twisted tape inserts.

Ranging from 60 to $180 \mathrm{Lph}$ of cold water, the effectiveness for plain tube, stainless steel constant and variable pitch, Aluminium constant and variable pitch, falls between $0.15-0.12,0.39-0.19,0.44-0.24,0.38-0.19,0.44-0.24$, respectively. This shows that the role of inserts to increase turbulence intensity is more significant in lower velocities as compared to higher velocities. The variation of friction factor (FF) with the mass flow rate for plain tube and tube fitted with various twisted tape is shown in Figure 3 (b). As expected, it was observed that the friction factor for constant and variable pitch twisted tape shows higher values of friction factor at a lower mass flow rate (Lph) of cold water as compared to the plain tube. Decrease in the swirling motion and blocking effect at the insert wall account for such observation [8-10]. It was observed that there was no such effect of material on the friction factor of the fluid.

\subsection{Simulation results}

The experimentally measured temperature and the pressure difference across the tube at various mass flow rates are compared with results obtained from CFD simulations as shown in Table 2 and 3.The reported error illustrated a reasonable agreement between the measured and the computational results. The pressure drop was noticeably increased when the twisted tape inserts were used in the tube. In addition, the results revealed that at various mass flow rates, cold water temperature difference obtained was maximum for variable pitch twisted tape as compared to constant tape inserts or plain tube. Figure 4shows the velocity distribution of cold water in the plain and twisted tape inserts. It was observed (table 4) that the velocity of the fluid in variable pitch twisted tape was lower as compared to the constant pitch twisted tape leading to an increase in the heat transfer rate. Figure 4 (a) and (b) reveals the variation of velocity intensity of cold water close to the wall and in the middle of the tube. The predicted magnitude of the velocity in twisted tape inserts was significantly higher as compared to plain tube due to the swirl motion of the fluid. 

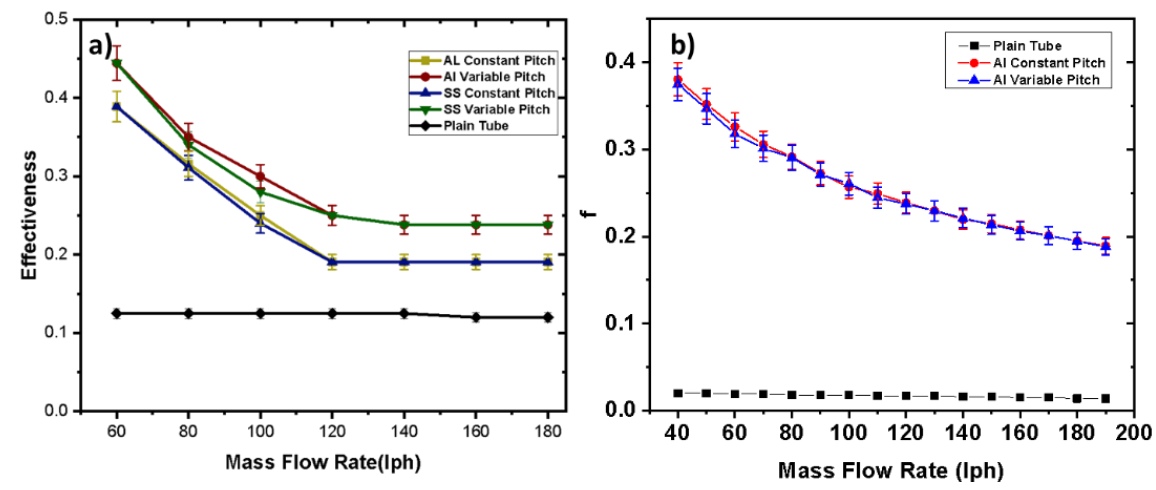

Fig. 3 (a). Plotted graph between Effectiveness $(E)$ and mass flow rate of cold water for various twisted tape inserts. (b) Plotted graph between friction factor (f) and mass flow rate of cold water for various twisted tape inserts.

Table 2 (a). Predicted and measured temperature across the test section with stainless steel twisted tape inserts as well as the prediction errors.

\begin{tabular}{|c|c|c|c|c|c|c|c|c|c|}
\hline & \multicolumn{3}{|c|}{ Plain Tube } & \multicolumn{3}{c|}{ S.S Constant Pitch } & \multicolumn{3}{c|}{ S.S Variable Pitch } \\
\hline $\begin{array}{c}\text { MFR } \\
(\mathrm{Lph})\end{array}$ & $\begin{array}{c}\mathrm{T}_{\text {avg }} \\
(\mathrm{CFD})\end{array}$ & $\begin{array}{c}\mathrm{T}_{\text {avg }} \\
(\text { Exp) }\end{array}$ & $\begin{array}{c}\text { Error } \\
(\%)\end{array}$ & $\begin{array}{c}\mathrm{T}_{\text {avg }} \\
(\mathrm{CFD})\end{array}$ & $\begin{array}{c}\mathrm{T}_{\text {avg }} \\
(\text { Exp })\end{array}$ & $\begin{array}{c}\text { Error } \\
(\%)\end{array}$ & $\begin{array}{c}\mathrm{T}_{\text {avg }} \\
(\mathrm{CFD})\end{array}$ & $\begin{array}{c}\mathrm{T}_{\text {avg }} \\
(\text { Exp })\end{array}$ & $\begin{array}{c}\text { Error } \\
(\%)\end{array}$ \\
\hline 40 & 38.00 & 37.45 & 1.44 & 43.00 & 42.00 & 2.32 & 43.50 & 42.50 & 2.29 \\
\hline 60 & 37.50 & 37.09 & 1.10 & 42.50 & 40.55 & 4.58 & 43.00 & 41.50 & 3.48 \\
\hline 120 & 37.50 & 36.78 & 1.92 & 41.00 & 39.70 & 3.17 & 41.50 & 40.35 & 2.77 \\
\hline 160 & 37.50 & 36.85 & 1.73 & 41.00 & 39.35 & 4.02 & 40.50 & 39.00 & 3.70 \\
\hline 180 & 37.50 & 37.00 & 1.33 & 41.00 & 39.00 & 4.87 & 40.50 & 38.85 & 4.07 \\
\hline
\end{tabular}

Table 2 (b). Predicted and measured temperature across the test section with aluminium twisted tape inserts as well as the prediction errors.

\begin{tabular}{|c|c|c|c|c|c|c|c|c|c|}
\hline & \multicolumn{3}{|c|}{ Plain Tube } & \multicolumn{3}{c|}{ Al Constant Pitch } & \multicolumn{3}{c|}{ Al Variable Pitch } \\
\hline $\begin{array}{c}\text { MFR } \\
(\text { Lph })\end{array}$ & $\begin{array}{c}T_{\text {avg }} \\
(\text { CFD) }\end{array}$ & $\begin{array}{c}T_{\text {avg }} \\
(\text { Exp) }\end{array}$ & $\begin{array}{c}\text { Error } \\
(\%)\end{array}$ & $\begin{array}{c}T_{\text {avg }} \\
(\text { CFD })\end{array}$ & $\begin{array}{c}T_{\text {avg }} \\
(\text { Exp })\end{array}$ & $\begin{array}{c}\text { Error } \\
(\%)\end{array}$ & $\begin{array}{c}T_{\text {avg }} \\
(\text { CFD })\end{array}$ & $\begin{array}{c}T_{\text {avg }} \\
(\text { Exp) }\end{array}$ & $\begin{array}{c}\text { Error } \\
(\%)\end{array}$ \\
\hline 40 & 38.00 & 37.45 & 1.44 & 41.00 & 40.27 & 1.78 & 43.50 & 42.85 & 1.49 \\
\hline 60 & 37.50 & 37.09 & 1.10 & 41.50 & 39.80 & 4.09 & 43.00 & 41.75 & 2.90 \\
\hline 120 & 37.50 & 36.78 & 1.92 & 40.00 & 39.45 & 1.37 & 40.50 & 39.95 & 1.35 \\
\hline 160 & 37.50 & 36.85 & 1.73 & 40.00 & 39.07 & 2.33 & 40.50 & 39.20 & 3.20 \\
\hline 180 & 37.50 & 37.00 & 1.33 & 40.00 & 38.75 & 3.12 & 40.50 & 38.94 & 3.86 \\
\hline
\end{tabular}

Table 3 (a). Predicted and measured pressure drop across the test section with stainless steel twisted tape inserts as well as the prediction errors.

\begin{tabular}{|c|c|c|c|c|c|c|c|c|c|}
\hline & \multicolumn{3}{|c|}{ Plain Tube } & \multicolumn{3}{c|}{ S.S constant Pitch } & \multicolumn{3}{c|}{ S.S Variable Pitch } \\
\hline $\begin{array}{c}\text { MFR } \\
(\mathrm{Lph})\end{array}$ & $\begin{array}{c}\Delta \mathrm{P} \\
(\mathrm{Exp})\end{array}$ & $\begin{array}{c}\Delta \mathrm{P} \\
(\mathrm{CFD})\end{array}$ & $\begin{array}{c}\text { Error } \\
(\%)\end{array}$ & $\begin{array}{c}\Delta \mathrm{P} \\
(\mathrm{Exp})\end{array}$ & $\begin{array}{c}\Delta \mathrm{P} \\
(\mathrm{CFD})\end{array}$ & $\begin{array}{c}\text { Error } \\
(\%)\end{array}$ & $\begin{array}{c}\Delta \mathrm{P} \\
(\mathrm{Exp})\end{array}$ & $\begin{array}{c}\Delta \mathrm{P} \\
(\mathrm{CFD})\end{array}$ & $\begin{array}{c}\text { Error } \\
(\%)\end{array}$ \\
\hline 40 & 4.15 & 4.00 & 3.61 & 38.90 & 38.00 & 2.31 & 37.00 & 35.00 & 5.40 \\
\hline 60 & 7.68 & 7.00 & 8.85 & 72.40 & 72.00 & 0.55 & 71.00 & 67.00 & 5.63 \\
\hline 120 & 11.78 & 11.00 & 6.62 & 202.0 & 195.00 & 3.46 & 149.00 & 144.00 & 3.35 \\
\hline 160 & 18.20 & 18.00 & 1.09 & 238.0 & 218.00 & 8.40 & 217.00 & 208.00 & 4.14 \\
\hline 180 & 19.50 & 19.00 & 2.56 & 279.0 & 264.00 & 5.37 & 265.00 & 243.00 & 8.30 \\
\hline
\end{tabular}


Table 5 (a) and 5 (b) shows the comparison of predicted and measured values of Nusselt number for various mass flows rate used in the experiment. The results show that increase in mass flow rate of cold water increases Nusselt number and eventually it leads to the augmentation of heat transfer rate and overall heat transfer coefficient. In addition, the predicted and calculated value of friction factors along the tube is shown in Table 6 (a) and 6 (b) and it revealed that the variable pitch twisted tape imposed higher friction factor compared to plain tube. Table 6(a) and 6(b) shows an agreement with those calculated from the experiment.

Table 3 (b). Predicted and measured pressure drop across the test section with aluminium twisted tape inserts as well as the prediction errors.

\begin{tabular}{|c|c|c|c|c|c|c|c|c|c|}
\hline & \multicolumn{3}{|c|}{ Plain Tube } & \multicolumn{3}{c|}{ Al Constant Pitch } & \multicolumn{3}{c|}{ Al Variable Pitch } \\
\hline $\begin{array}{c}\text { MFR } \\
(\mathrm{Lph})\end{array}$ & $\begin{array}{c}\Delta \mathrm{P} \\
(\mathrm{Exp})\end{array}$ & $\begin{array}{c}\Delta \mathrm{P} \\
(\mathrm{CFD})\end{array}$ & $\begin{array}{c}\text { Error } \\
(\%)\end{array}$ & $\begin{array}{c}\Delta \mathrm{P} \\
(\mathrm{Exp})\end{array}$ & $\begin{array}{c}\Delta \mathrm{P} \\
(\mathrm{CFD})\end{array}$ & $\begin{array}{c}\text { Error } \\
(\%)\end{array}$ & $\begin{array}{c}\Delta \mathrm{P} \\
(\mathrm{Exp})\end{array}$ & $\begin{array}{c}\Delta \mathrm{P} \\
(\mathrm{CFD})\end{array}$ & $\begin{array}{c}\text { Error } \\
(\%)\end{array}$ \\
\hline 40 & 4.15 & 4.00 & 3.61 & 37.60 & 37.00 & 1.59 & 38.00 & 36.00 & 5.26 \\
\hline 60 & 7.68 & 7.00 & 8.85 & 77.00 & 70.00 & 9.09 & 74.00 & 71.00 & 4.05 \\
\hline 120 & 11.78 & 11.00 & 6.62 & 201.00 & 197.00 & 1.99 & 148.00 & 146.00 & 1.35 \\
\hline 160 & 18.20 & 18.00 & 1.09 & 234.00 & 217.00 & 7.26 & 215.00 & 206.00 & 4.18 \\
\hline 180 & 19.50 & 19.00 & 2.56 & 276.00 & 264.00 & 4.34 & 257.00 & 244.00 & 5.05 \\
\hline
\end{tabular}

Table 4. Velocity values $(\mathrm{m} / \mathrm{s})$ of water for different insert configuration at various mass flow rate.

\begin{tabular}{|c|c|c|c|c|c|}
\hline \multirow{2}{*}{ MFR (Lph) } & Plain Tube & $\begin{array}{c}\text { S.S constant } \\
\text { Pitch }\end{array}$ & $\begin{array}{c}\text { S.S Variable } \\
\text { Pitch }\end{array}$ & $\begin{array}{c}\text { Al Constant } \\
\text { Pitch }\end{array}$ & $\begin{array}{c}\text { Al Variable } \\
\text { Pitch }\end{array}$ \\
\cline { 2 - 6 } & \multicolumn{5}{|c|}{ Velocity (m/s) } \\
\hline 40 & 0.062 & 0.053 & 0.065 & 0.032 & 0.033 \\
\hline 60 & 0.088 & 0.102 & 0.098 & 0.050 & 0.052 \\
\hline 120 & 0.124 & 0.169 & 0.127 & 0.128 & 0.101 \\
\hline 160 & 0.166 & 0.181 & 0.168 & 0.137 & 0.134 \\
\hline 180 & 0.175 & 0.200 & 0.193 & 0.156 & 0.152 \\
\hline
\end{tabular}

Table 5 (a). Comparison between predicted and measured Nusselt number of the test section with stainless steel twisted tape inserts as well as the prediction errors.

\begin{tabular}{|c|c|c|c|c|c|c|c|c|c|}
\hline & \multicolumn{3}{|c|}{ Plain Tube } & \multicolumn{2}{c|}{ S.S constant Pitch } & \multicolumn{2}{c|}{ S.S Variable Pitch } \\
\hline $\begin{array}{c}\text { MFR } \\
(\mathrm{Lph})\end{array}$ & $\begin{array}{c}\mathrm{Nu} \\
(\mathrm{Exp})\end{array}$ & $\begin{array}{c}\mathrm{Nu} \\
(\mathrm{CFD})\end{array}$ & $\begin{array}{c}\text { Error } \\
(\%)\end{array}$ & $\begin{array}{c}\mathrm{Nu} \\
(\mathrm{Exp})\end{array}$ & $\begin{array}{c}\text { Nu } \\
(\mathrm{CFD})\end{array}$ & $\begin{array}{c}\text { Error } \\
(\%)\end{array}$ & $\begin{array}{c}\text { Nu } \\
(\text { Exp) }\end{array}$ & $\begin{array}{c}\text { Nu } \\
(\mathrm{CFD})\end{array}$ & $\begin{array}{c}\text { Error } \\
(\%)\end{array}$ \\
\hline 40 & 13.64 & 13.57 & 0.53 & 14.32 & 14.18 & 0.94 & 14.38 & 14.25 & 0.94 \\
\hline 60 & 18.78 & 18.70 & 0.40 & 19.71 & 19.34 & 1.85 & 19.80 & 19.52 & 1.42 \\
\hline 120 & 29.73 & 29.48 & 0.83 & 30.95 & 30.49 & 1.46 & 31.12 & 30.72 & 1.29 \\
\hline 160 & 37.43 & 37.14 & 0.75 & 38.95 & 38.23 & 1.85 & 38.73 & 38.08 & 1.69 \\
\hline 180 & 41.12 & 40.89 & 0.57 & 42.80 & 41.84 & 2.24 & 42.56 & 41.77 & 1.86 \\
\hline
\end{tabular}

Table 5 (b). Comparison between predicted and measured Nusselt number of the test section with aluminium twisted tape inserts as well as the prediction errors.

\begin{tabular}{|c|c|c|c|c|c|c|c|c|c|}
\hline & \multicolumn{3}{|c|}{ Plain Tube } & \multicolumn{3}{c|}{ Al Constant Pitch } & \multicolumn{3}{c|}{ Al Variable Pitch } \\
\hline $\begin{array}{c}\text { MFR } \\
(\mathrm{Lph})\end{array}$ & $\begin{array}{c}\mathrm{Nu} \\
(\mathrm{Exp})\end{array}$ & $\begin{array}{c}\mathrm{Nu} \\
(\mathrm{CFD})\end{array}$ & $\begin{array}{c}\text { Error } \\
(\%)\end{array}$ & $\begin{array}{c}\text { Nu } \\
(\text { Exp })\end{array}$ & $\begin{array}{c}\mathrm{Nu} \\
(\mathrm{CFD})\end{array}$ & $\begin{array}{c}\text { Error } \\
(\%)\end{array}$ & $\begin{array}{c}\mathrm{Nu} \\
(\text { Exp })\end{array}$ & $\begin{array}{c}\text { Nu } \\
(\mathrm{CFD})\end{array}$ & $\begin{array}{c}\text { Error } \\
(\%)\end{array}$ \\
\hline 40 & 13.64 & 13.57 & 0.53 & 14.25 & 14.08 & 1.15 & 14.38 & 14.30 & 0.61 \\
\hline 60 & 18.78 & 18.70 & 0.40 & 19.52 & 19.20 & 1.62 & 19.80 & 18.95 & 4.29 \\
\hline 120 & 29.73 & 29.48 & 0.83 & 30.60 & 30.41 & 0.62 & 30.77 & 30.58 & 0.62 \\
\hline 160 & 37.43 & 37.14 & 0.75 & 38.52 & 38.11 & 1.06 & 38.73 & 38.17 & 1.46 \\
\hline 180 & 41.12 & 40.89 & 0.57 & 42.32 & 41.72 & 1.41 & 42.56 & 41.81 & 1.76 \\
\hline
\end{tabular}


Table 6 (a). Comparison between predicted and measured friction factor of the test section with stainless steel twisted tape inserts as well as the prediction errors.

\begin{tabular}{|c|c|c|c|c|c|c|c|c|c|}
\hline & \multicolumn{3}{|c|}{ Plain Tube } & \multicolumn{3}{c|}{ S.S constant Pitch } & \multicolumn{3}{c|}{ S.S Variable Pitch } \\
\hline $\begin{array}{c}\text { MFR } \\
(\text { Lph })\end{array}$ & $\begin{array}{c}f \\
(\text { Exp })\end{array}$ & $\begin{array}{c}f \\
(\text { CFD })\end{array}$ & $\begin{array}{c}\text { Error } \\
(\%)\end{array}$ & $\begin{array}{c}f \\
(\text { Exp })\end{array}$ & $\begin{array}{c}f \\
(\text { CFD })\end{array}$ & $\begin{array}{c}\text { Error } \\
(\%)\end{array}$ & $\begin{array}{c}f \\
(E x p)\end{array}$ & $\begin{array}{c}f \\
(C F D)\end{array}$ & $\begin{array}{c}\text { Error } \\
(\%)\end{array}$ \\
\hline 40 & 0.020 & 0.020 & 1.13 & 0.40 & 0.38 & 6.35 & 0.39 & 0.38 & 3.75 \\
\hline 60 & 0.019 & 0.018 & 2.63 & 0.35 & 0.32 & 8.99 & 0.34 & 0.33 & 2.29 \\
\hline 120 & 0.017 & 0.016 & 5.34 & 0.26 & 0.24 & 7.30 & 0.26 & 0.26 & 0.77 \\
\hline 160 & 0.015 & 0.015 & 1.65 & 0.23 & 0.22 & 3.34 & 0.23 & 0.21 & 6.62 \\
\hline 180 & 0.014 & 0.014 & 0.42 & 0.21 & 0.20 & 6.95 & 0.21 & 0.20 & 6.95 \\
\hline
\end{tabular}

Table 6 (b). Comparison between predicted and measured friction factor of the test section with aluminium twisted tape inserts as well as the prediction errors.

\begin{tabular}{|c|c|c|c|c|c|c|c|c|c|}
\hline & \multicolumn{3}{|c|}{ Plain Tube } & \multicolumn{3}{c|}{ Al Constant Pitch } & \multicolumn{3}{c|}{ Al Variable Pitch } \\
\hline $\begin{array}{c}\text { MFR } \\
(\text { Lph })\end{array}$ & $\begin{array}{c}\mathrm{f} \\
(\text { Exp) }\end{array}$ & $\begin{array}{c}\mathrm{f} \\
(\mathrm{CFD})\end{array}$ & $\begin{array}{c}\text { Error } \\
(\%)\end{array}$ & $\begin{array}{c}\mathrm{f} \\
(\text { Exp) }\end{array}$ & $\begin{array}{c}\mathrm{f} \\
(\mathrm{CFD})\end{array}$ & $\begin{array}{c}\text { Error } \\
(\%)\end{array}$ & $\begin{array}{c}\mathrm{f} \\
(\text { Exp })\end{array}$ & $\begin{array}{c}\mathrm{f} \\
(\mathrm{CFD})\end{array}$ & $\begin{array}{c}\text { Error } \\
(\%)\end{array}$ \\
\hline 40 & 0.020 & 0.020 & 1.13 & 0.38 & 0.37 & 2.74 & 0.37 & 0.36 & 4.72 \\
\hline 60 & 0.019 & 0.018 & 2.63 & 0.33 & 0.31 & 4.94 & 0.32 & 0.29 & 7.73 \\
\hline 120 & 0.017 & 0.016 & 5.34 & 0.24 & 0.23 & 3.73 & 0.24 & 0.22 & 7.36 \\
\hline 160 & 0.015 & 0.015 & 1.65 & 0.21 & 0.20 & 5.50 & 0.21 & 0.21 & 0.55 \\
\hline 180 & 0.014 & 0.014 & 0.42 & 0.19 & 0.19 & 2.30 & 0.19 & 0.19 & 3.85 \\
\hline
\end{tabular}

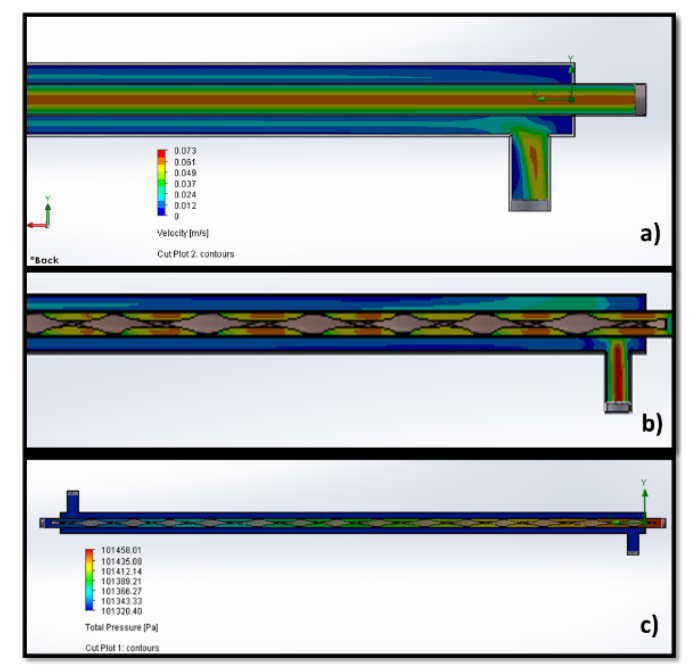

Fig. 4. Velocity distribution of fluid inside (a) plain tube and (b) aluminium variable pitch twisted tape (c) Pressure drop across the tube.

\section{Conclusions}

The key point of the paper is the modified geometry of the twisted tape insert, which is termed as variable pitch twisted tape insert (4-3-4). The heat transfer characteristics of the 
tape were studied for two different material i.e. stainless steel and aluminium. Moreover, experimental results were validated with computational fluid dynamics simulation results. Based on the results, the aluminium variable pitch twisted tape insert showed higher heat transfer rate and overall heat transfer coefficient in comparison with the plain and constant pitch twisted tape. The modified constant pitch twisted tape showed enhanced overall heat transfer coefficient of $67.14 \%$ as compared to the plain tube. However, aluminium variable pitch insert showed an enhancement of overall heat transfer coefficient by $18.15 \%$ as compared to aluminium constant pitch insert. Whereas, the stainless-steel variable pitch insert showed enhancement of $15.25 \%$ as compared to its constant pitch insert. The computational fluid dynamics modelling was used for supporting and explaining the results obtained experimentally. The simulated results were in proper agreement with the experimental results having error ranging from 1-5\%.The swirl flow and high turbulence intensity of the fluid near the wall surface has been expressed as one of the major reasons for enhances heat transfer and performance while using the variable pitch twisted tape.

\section{References}

1. S. Martemianov, V. L. Okulov, Int. J. Heat Mass Transfer 47, 2379-2393 (2004)

2. E. Smithberg, F. Landies, ASME J. Heat Transfer 86, 39-49 (1964)

3. R. L. Webb, V. Narayanmurthy, P. Thors, ASME J. Heat Transfer 122, 134-142 (2000)

4. S Eiamsaard, C. Thianpong, P. Promvonge, Int. Commun. Heat Mass Transfer 33, 1225-1233 (2006)

5. P. K. Sarma, P. S. Kishore, R. V. Dharma, T. Subrahmanyam, Int. J. Therm. Sci. 44, 393-398 (2005)

6. S.K. Agarwal, R. M. Raja, Int. J. Heat Mass Transfer 39, 3547-3557 (1996)

7. S. W. Chang, Y. J. Jan, J. S. Liou, Int. J. Therm. Sci. 46,506-518 (2007)

8. R. M. Manglik, A. E. Bergles, ASME J. Heat Transfer 115, 881-889 (1993)

9. V. Yakhot, S. A. Orszag, J. Sci. Comput. 1, 3-51 (1986)

10. B. E. Launder, D. B. Spalding, Compute. Method Appl. Mech. Eng. 3, 269-289 (1974) 